\title{
DEFLAGRATION-TO-DETONATION TRANSITION UNDER INITIATION BY HIGH-VOLTAGE NANOSECOND DISCHARGES
}

\author{
A. E. Rakitin, V.P. Zhukov, and A. Yu. Starikovskii
}

\begin{abstract}
Experimental study of detonation initiation by high-voltage pulsed gas discharges has been performed in three detonation tubes. It was shown in the experiments that distributed nanosecond discharge is significantly more efficient for detonation initiation than localized microsecond discharge of comparable energy. For a detailed experimental study of deflagration-to-detonation transition (DDT), a detonation tube with a single discharge cell and nanosecond initiation has been assembled. Optical observation of the discharge development, ignition, and DDT process was performed with an intensified charge-coupled device (ICCD) camera. A mechanism of detonation initiation by high-voltage nanosecond discharges has been proposed.
\end{abstract}

\section{INTRODUCTION}

The goal of this work is the reduction of the DDT length and time in smooth detonation tubes under minimum energy of initiation. The DDT length and time are crucial parameters for pulse detonation engine (PDE) applications. Thus, it is necessary to find an effective means for detonation initiation.

For direct detonation initiation, a considerable energy deposition into the mixture is required. For stoichiometric propane-air mixture, experiments yield minimum initiation energy of $0.08 \mathrm{~kg}$ in TNT equivalent or $300 \mathrm{~kJ}$ for spherical detonation [1]. When initiated in a tube by a lower energy source, the DDT may occur at the distance of several tens of tube diameters away from the initiation point. The most common method of reducing the DDT length consists in using various types of obstacles, which disturb the flow and increase the flame velocity [2-7]. A variant of this method is the application of a two-chamber initiating system which implies that the mixture is ignited in the first chamber, whereas a detonation wave is initiated in the second chamber by hot turbulent jets [4-6, 8]. In this case, the acceleration of the flame front depends on its own speed and power. If the initial flame front velocity is low, flow turbulization and consequent flame acceleration are weak. Usually, the initial flame front is weak which leads to a relatively low efficiency of this method. This concept was realized experimentally [8]; Chapman-Jouguet (CJ) detonation mode was obtained at $2 \mathrm{~m}$ in

This is an Open Access article distributed under the terms of the Creative Commons Attribution-Noncommercial License 3.0, which permits unrestricted use, distribution, and reproduction in any noncommercial medium, provided the original work is properly cited. 
a 15-centimeter diameter tube with regularly spaced obstacles in a $\mathrm{C}_{3} \mathrm{H}_{8}+5 \mathrm{O}_{2}$ $+15 \mathrm{~N}_{2}$ mixture at 1 bar. The use of a precombustion chamber for turbulent flame ejection allowed one to decrease the DDT time from 24 to $14 \mathrm{~ms}$ but at the same time, no effect on the DDT length was found.

Coherent ignition technique was used for detonation initiation in other works [9]. In the experiments, the mixture was ignited by a set of spark plugs installed along the smooth-walled detonation tube. Different delay times for each spark plug were chosen in order to obtain maximum flame front acceleration. The DDT length of $0.6-0.7 \mathrm{~m}$ was achieved in a propane-air mixture at 1 bar. This technique allowed to reach a detonation initiation energy of $1.68 \mathrm{MJ} / \mathrm{m}^{2}$ which is less in comparison to the initiation by TNT [1] but is still higher than for the case of nonequilibrium plasma igniters.

In [10], it was found that the critical energy of initiation by a spark decreases as the power density of the initiating source increases. A number of scientific teams carried out investigations of ignition by nonequilibrium corona discharges $[11,12]$. The experiments were performed for ethylene-air, propaneair [12], and methane-air [11] mixtures. The authors applied a pulsed nanosecond discharge with a duration of $50 \mathrm{~ns}$. They performed a comparison of the induction delay times under the ignition by the corona and by a conventional spark discharge with the same energy. The induction delay times were shortened by a factor of 3-5 under the ignition by the pulsed corona discharge.

A nanosecond discharge in the form of a fast ionization wave (FIW) as a source of ignition has a set of advantages $[13,14]$ : high spatial uniformity, high efficiency of formation of reactive species, high power, and coherence, that is, simultaneous excitation of the mixture in a bulk volume. A theoretical study of such application of nanosecond discharges was performed by Kukaev et al. [14]. It was confirmed that formation of a strong shock wave from compression waves arises if the typical time of the chemical energy release is shorter than the time of the gasdynamic processes under the selected initial conditions and mixture composition. It was also shown that the DDT length and time are shorter under fast energy release and low temperatures.

Nonequilibrium nanosecond discharge is also promising for detonation initiation from the point of view of Zel'dovich's gradient mechanism [15]. Through this mechanism, a successful DDT may be obtained at shorter distances in a medium with an induction time gradient. It has been shown [14] that a fast ionization wave allows one to produce active species in a bulk volume. If a proper geometry and parameters of the discharge device are chosen, this may lead to formation of the required induction time gradient.

In the current work, three setups have been assembled to study detonation initiation. In the first, the mixture is ignited by a distributed high-voltage nonequilibrium nanosecond discharge which excites the mixture in a bulk volume across the tube. In the second, the mixture is ignited by a localized high-voltage microsecond spark discharge. The third detonation tube is equipped with a 
single-cell initiator for a detailed study of initiation by nanosecond discharges of different types. The discharge energies and the geometries of the discharge sections in all these cases were comparable which allowed direct comparison of the efficiencies of different detonation initiation means.

\section{DETONATION INITIATION BY DISTRIBUTED NANOSECOND DISCHARGE}

The experimental setup used for studying detonation initiation by a distributed high-voltage nanosecond discharge is described in detail in authors' previous works $[16,17]$. The experiments were carried out in a detonation tube with inner diameter of $140 \mathrm{~mm}$. The discharge was initiated by a 60-nanosecondlong high-voltage pulse with 12-nanosecond rise time. Voltage amplitude ranged from 4 to $70 \mathrm{kV}$, the corresponding energy input ranged from $70 \mathrm{~mJ}$ to $14 \mathrm{~J}$. The discharge section was a distributed electrode system consisting of 131 discharge cells placed over the tube cross section [18]. The pulse parameters were registered by a back-current shunt and a capacitive gauge. Flame propagation velocity was registered by 5 infrared (IR) sensors installed along the detonation tube. Shock wave propagation velocity was measured simultaneously by 2 Schlieren sensors.

The discharge development was studied with an ICCD camera (LaVision Picostar 12HR) with nanosecond temporal resolution. The main contribution to the intensity of discharge radiation was made by $C^{3} \Pi_{u}, v^{\prime}=0 \rightarrow B^{3} \Pi_{g}, v^{\prime \prime}=0$ band of nitrogen at $337 \mathrm{~nm}$. A series of images for the discharge development in air at 0.33 bar is presented in Fig. 1. Dark dots in the images correspond to the radiation of single discharge cells. The discharge had three temporal stages. During the first stage (0-15 ns), emission intensity rose steeply, reaching its maximum value. The emission at this stage was distributed quasi-homogeneously over the discharge section. During the second stage (15-50 ns), the intensity decreased sharply. The third stage $(t>200 \mathrm{~ns})$ was the afterglow stage, when the emission was localized within 1-2 discharge cells. Emission intensity of each subsequent stage decreased by about an order of magnitude comparing to the preceding one.

The experiments on detonation initiation were carried out for different stoichiometric mixtures: $\mathrm{C}_{3} \mathrm{H}_{8}+5 \mathrm{O}_{2}+x \mathrm{~N}_{2}(0 \leq x \leq 4) ; \mathrm{C}_{3} \mathrm{H}_{8} / \mathrm{C}_{4} \mathrm{H}_{10}+5 \mathrm{O}_{2}$ $+x \mathrm{~N}_{2}(0 \leq x \leq 10) ; 0.5 \mathrm{C}_{6} \mathrm{H}_{14}+4.5 \mathrm{O}_{2}+x \mathrm{~N}_{2}(0 \leq x \leq 3) ;$ and $\mathrm{C}_{3} \mathrm{H}_{8} / \mathrm{C}_{4} \mathrm{H}_{10}$ + air. Initial pressure values varied from 0.15 to 1 bar. In the experiments, flame front velocity, shock wave velocity, and ignition delay times were measured simultaneously with initial mixture pressure, nitrogen dilution level, and nanosecond pulse parameters. The comparison of shock wave velocities obtained with Schlieren sensors and flame front velocities obtained with IR sensors showed that the velocities coincided in all supersonic propagation modes. This proved the possibility to use IR emission diagnostics for DDT study and allowed com- 


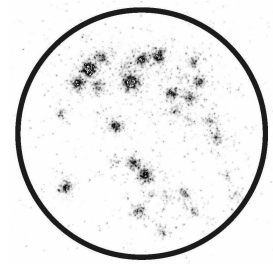

(a)

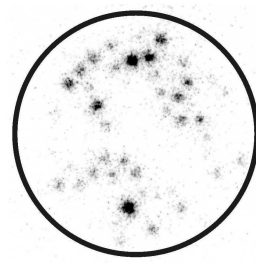

(b)

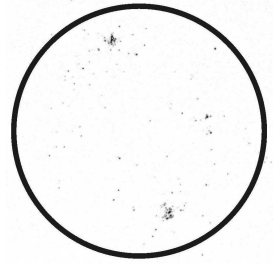

(c)

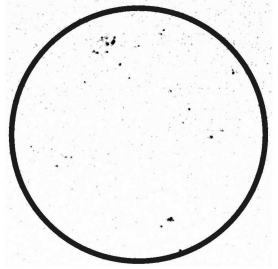

(d)

Figure 1 Negative images of nanosecond discharge development in air at 0.33 bar at different moments in time. Front view. The line corresponds to the edge of the discharge chamber cross section. Camera gate: 3 ns. Time was counted off from the moment when the back-current shunt signal reached half of the maximum value: (a) $t=0 \mathrm{~ns}$, intensity $\times 2$; (b) $t=6 \mathrm{~ns}$, intensity $\times 1$; (c) $t=30 \mathrm{~ns}$, intensity $\times 8$; and (d) $t=240 \mathrm{~ns}$, intensity $\times 16$

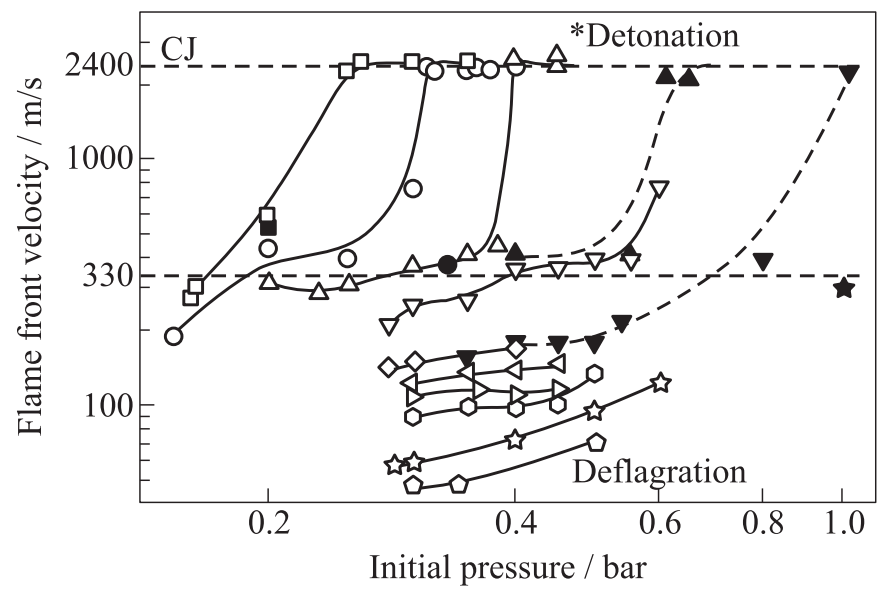

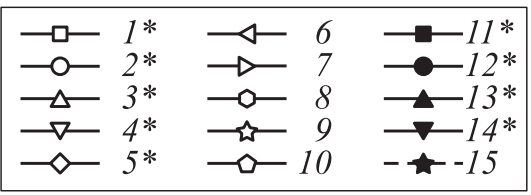

Figure 2 Flame front velocity as a function of initial mixture pressure for different mixture compositions under ignition by distributed nanosecond discharge: $\mathrm{C}_{3} \mathrm{H}_{8} / \mathrm{C}_{4} \mathrm{H}_{10}+5 \mathrm{O}_{2}+x \mathrm{~N}_{2}: 1-x=0(0 \%) ; 2-1(14 \%) ; 3-2(25 \%) ; 4-3$ $(33 \%) ; 5-4(40 \%) ; 6-5(45 \%) ; 7-6(50 \%) ; 8-7(54 \%) ; 9-8(57 \%) ; 10-$ $x=10(63 \%) ; 0.5 \mathrm{C}_{6} \mathrm{H}_{14}+4.5 \mathrm{O}_{2}+x \mathrm{~N}_{2}: 11-x=0(0 \%) ; 12-1.5(23 \%) ; 13-2.3$ $(32 \%) ; 14-3(38 \%)$; and $15-\mathrm{C}_{3} \mathrm{H}_{8} / \mathrm{C}_{4} \mathrm{H}_{10}+$ air 
paring the velocity values obtained with the IR sensors with those obtained with the pressure transducers in the supersonic modes.

Under the current experimental conditions, three modes of flame propagation were observed: deflagration, with subsonic propagation velocities, transient detonation, with supersonic velocities and high values of flame front acceleration along the tube, and CJ detonation obtained under lower nitrogen dilution levels or higher initial pressures. The measured velocity of flame front propagation agreed well with the corresponding calculated values. The results of these experiments are presented in Fig. 2 in terms of dependencies of the flame front propagation velocity $400 \mathrm{~mm}$ ( $\sim 3$ tube diameters) away from the discharge chamber upon the initial mixture pressure, for different mixture compositions. Velocity values of $\sim 2400 \mathrm{~m} / \mathrm{s}$ for propane/butane mixtures and $\sim 2100 \mathrm{~m} / \mathrm{s}$ for hexane mixtures correspond to the cases where CJ detonations were obtained.

The DDT was observed $400 \mathrm{~mm}$ away from the discharge chamber or closer in all mixtures with nitrogen dilution level up to $38 \%$. The energy input in these cases did not exceed 3 J. For undiluted stoichiometric propane-oxygen mixture, the DDT length and time under energy input of $70 \mathrm{~mJ}$ amounted to $130 \mathrm{~mm}$ and $0.6 \mathrm{~ms}$, respectively. This value of energy input corresponded to $4 \mathrm{~J} / \mathrm{m}^{2}$ specific energy. In $0.5 \mathrm{C}_{6} \mathrm{H}_{14}+4.5 \mathrm{O}_{2}+3 \mathrm{~N}_{2}$ mixture $\left(38 \% \mathrm{~N}_{2}\right)$, the DDT length under energy input of $3 \mathrm{~J}$ at initial pressure of 1 bar was $300 \mathrm{~mm}$, the DDT time was $0.6 \mathrm{~ms}$. It is also seen from Fig. 2 that flame front velocities in propane/butane and hexane mixtures are the same for mixtures with the same values of nitrogen dilution, for which the combustion heat values are also close.

\section{DETONATION INITIATION BY MICROSECOND SPARK DISCHARGE}

For comparison between detonation initiation and flame propagation modes under initiation by different kinds of discharge, a new setup has been assembled. The setup scheme is presented in Fig. $3 a$. The inner diameter and the length of the detonation tube 1 were 53 and $1000 \mathrm{~mm}$, respectively. The discharge chamber 2 was mounted to one end of the tube. The geometry of the discharge chamber pictured in Fig. $3 b$ was analogous to the one used for nanosecond detonation initiation. The high-voltage (HV) electrode was a distributed electrode system consisting of 28 pins separated from each other and from the ground electrode by a ceramic insulator. Each pin formed a discharge cell with interelectrode gap of $50 \mathrm{~mm}$. The direct current (DC) power supply 3 charged the feeding line 4 up to a voltage of $37 \mathrm{kV}$. A high-voltage pulse was formed on the electrode when the feeding line had been grounded by the thyratron 5 . The pulse parameters were registered by the back-current shunt 6 . For shock and detonation wave velocity measurement, piezoelectric pressure transducers 7 were used. The transducers were installed in the sidewalls of the tube at distances of 3,363 , and $873 \mathrm{~mm}$ 


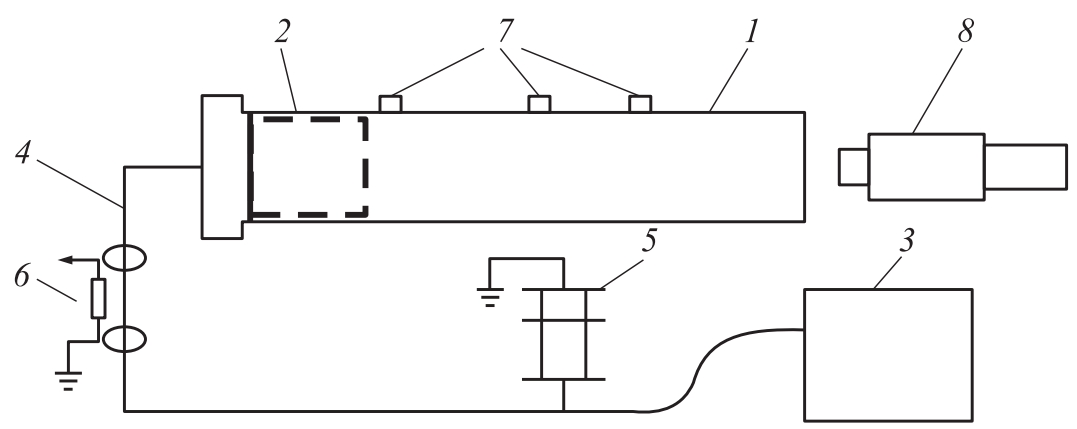

(a)
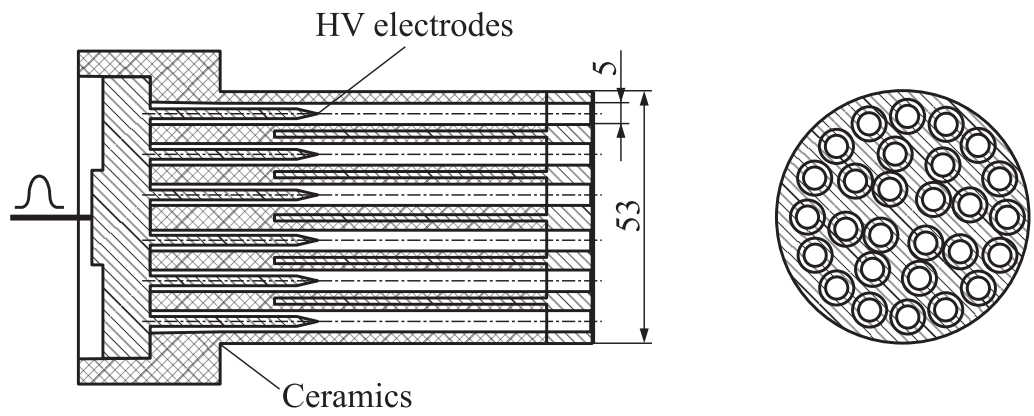

(b)

Figure 3 The setup for detonation initiation by microsecond spark discharge. (a) Principal scheme of the setup: 1 - detonation tube; 2 - discharge chamber; 3 - DC power supply; 4 - high-voltage feeding line; $Z=17 \mathrm{Ohm} ; 5$ - thyratron; 6 - back-current shunt; 7 - piezoelectric pressure transducers; and 8- ICCD camera with nanosecond resolution. (b) Discharge chamber 2 consisting of 28 discharge cells: chamber diameter is $53 \mathrm{~mm}$, discharge cell diameter is $5 \mathrm{~mm}$, discharge cell length is $95 \mathrm{~mm}$, and interelectrode gap is $50 \mathrm{~mm}$ [18]

from the discharge chamber. The pulse parameters were the following: amplitude $37 \mathrm{kV}$, width $1-3 \mu \mathrm{s}$, and rise time $\sim 100 \mathrm{~ns}$. The rise time was determined by the thyratron switching time. The energy input in this case was limited by the energy stored in the feeding line which was equal to $14 \mathrm{~J}$. The actual energy input value was not measured during the experiments.

The discharge development for this electrode configuration and pulse parameters was studied with the LaVision Picostar 12HR ICCD camera 8. The images were taken through the end of the detonation tube within a spectral range of $300-800 \mathrm{~nm}$. The spatially resolved ICCD images of discharge development in air at 1 bar are presented in Fig. 4. Time is counted off from the moment of 


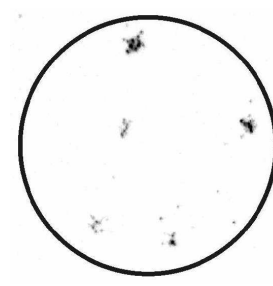

(a)

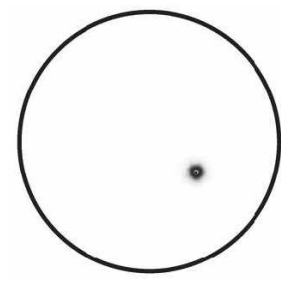

(b)

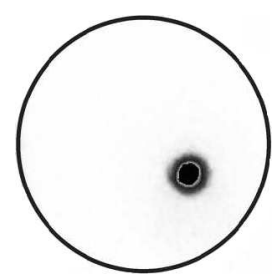

(c)

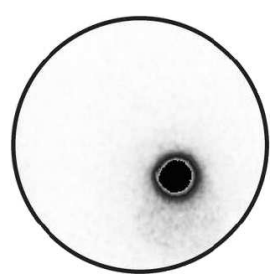

(d)

Figure 4 Negative images of the microsecond discharge development in air at 1 bar at different time instants. Front view. Black line corresponds to the edge of the discharge chamber cross-section. (a) 25-50 ns, Gate $25 \mathrm{~ns}$, intensity $\times 16$; (b) $50 \mathrm{~ns}$, Gate $1 \mathrm{~ns}$, intensity $\times 1$; $(c) 65 \mathrm{~ns}$, Gate $1 \mathrm{~ns}$, intensity $\times 1$; and $(d) 230 \mathrm{~ns}$, Gate $1 \mathrm{~ns}$, intensity $\times 1$

electrical pulse reaching the electrode. In Fig. $4 a$, the streamer phase of discharge development is presented. The intensity of emission at this stage was extremely low. The discharge localization and spark formation due to ionization instability occurred sooner than $\sim 50 \mathrm{~ns}$ after the pulse had reached the electrode. The spark stage of discharge development is presented in Figs. $4 b$ to $4 d$. It was during these stages when most of the pulse energy consumption occurred. Homogeneous discharge phase was not observed at all in most of the discharge cells. Such discharge development pattern is a result of a relatively long pulse rise time $(\sim 100 \mathrm{~ns})$.

Experiments on detonation initiation by a high-voltage microsecond discharge were carried out in two propane/butane mixtures $\left(\mathrm{C}_{3} \mathrm{H}_{8} / \mathrm{C}_{4} \mathrm{H}_{10}+5 \mathrm{O}_{2}+x \mathrm{~N}_{2}\right.$ with $x=0$ and $x=4$ ) at initial pressures up to 1 bar. The mode of flame propagation was determined by shock wave velocity measured with pressure transducers. As shown in Section 2, flame front velocity coincides with shock wave velocity in all supersonic modes of propagation. The results of these experiments are presented in Fig. 5 (solid lines, solid symbols) in terms of dependencies of the shock wave velocity $600 \mathrm{~mm}$ away from the discharge chamber upon the initial mixture pressure for different mixture compositions. The results are presented in comparison with the ones obtained in the same mixtures under initiation by a nanosecond discharge and described in Section 2 (dashed lines and hollow symbols). It needs to be noted that these results are only to be compared in the region of supersonic propagation velocities.

The same modes of flame propagation were observed in these experiments: deflagration, transient detonation, and CJ detonation. For the undiluted mixture (solid circles), detonation was observed at 0.6 bar of initial pressure under initiation by a microsecond spark, whereas in the case of initiation by a nonequilibrium nanosecond discharge, the DDT was obtained at essentially lower pressure of 0.25 bar. For the mixture with nitrogen dilution level $x=4$, detonation was only observed under nanosecond initiation. In the case of microsecond spark 


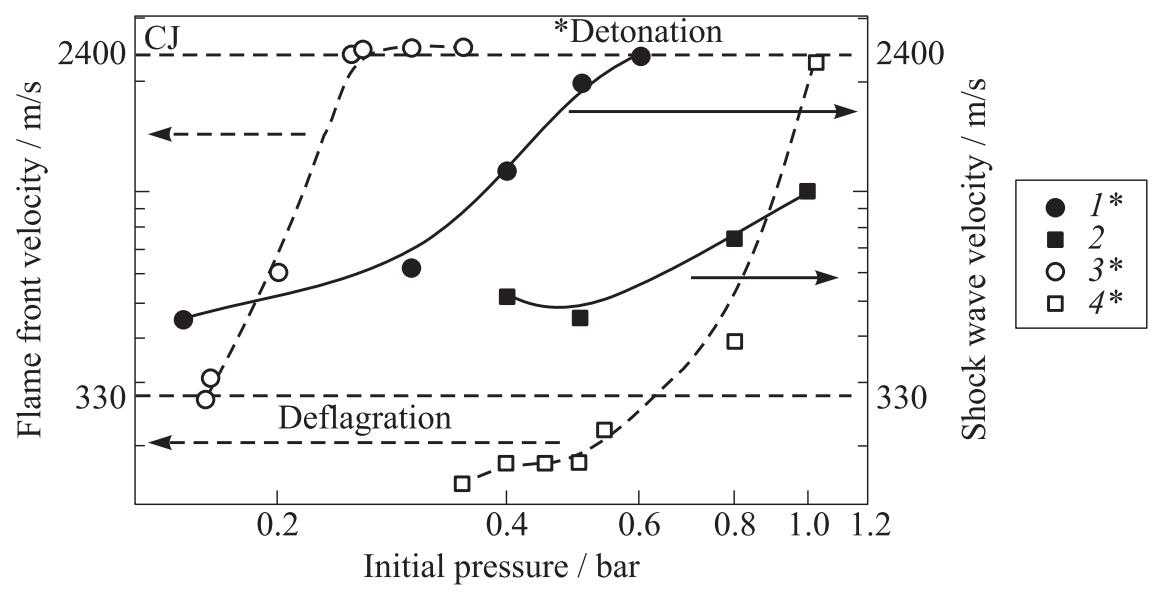

Figure 5 Flame front velocity as a function of initial pressure for different mixture compositions. Solid lines and solid symbols are for microsecond initiation, dashed lines and hollow symbols are for nanosecond initiation: 1 $\mathrm{C}_{3} \mathrm{H}_{8} / \mathrm{C}_{4} \mathrm{H}_{10}+5 \mathrm{O}_{2} ; 2-\mathrm{C}_{3} \mathrm{H}_{8} / \mathrm{C}_{4} \mathrm{H}_{10}+5 \mathrm{O}_{2}+4 \mathrm{~N}_{2} ; 3-\mathrm{C}_{3} \mathrm{H}_{8} / \mathrm{C}_{4} \mathrm{H}_{10}+5 \mathrm{O}_{2}$; and $4-0.5 \mathrm{C}_{6} \mathrm{H}_{14}+4.5 \mathrm{O}_{2}+3 \mathrm{~N}_{2}$

initiation, at maximum initial pressure of 1 bar, transient detonation mode with flame front velocity of $\sim 1000 \mathrm{~m} / \mathrm{s}$ was observed. This indicates essentially higher efficiency of a distributed quasi-homogeneous nonequilibrium discharge as a detonation initiator. Simultaneously, ignition delay time dependence upon initial mixture pressure and nitrogen dilution level was measured in the same experiments. It was found that ignition delay times were substantially lower for the microsecond ignition in all the mixtures at initial pressures up to $\sim 0.5$ bar when compared to the nanosecond ignition. This fact pointed at the higher efficiency of the localized microsecond discharge as an ignition source.

\section{DETONATION INITIATION BY NANOSECOND DISCHARGE IN A SINGLE-CELL GEOMETRY}

For a detailed experimental study of DDT, a detonation tube with a single-cell geometry of the discharge chamber and nanosecond initiation has been assembled (Fig. 6). The chamber geometry was similar to the cell geometry of the distributed electrode system described in Section 2. The discharge cell diameter was $6.5 \mathrm{~mm}$, the interelectrode gap could be varied from 30 to $150 \mathrm{~mm}$. The discharge was initiated by a 50-nanosecond-long 160-kilovolt high-voltage pulse with 20 -nanosecond rise time. The incident pulse energy amounted to $\sim 20 \mathrm{~J}$. The detonation tube mounted at the output of the discharge cell was of $20 \times 20 \mathrm{~mm}$ 


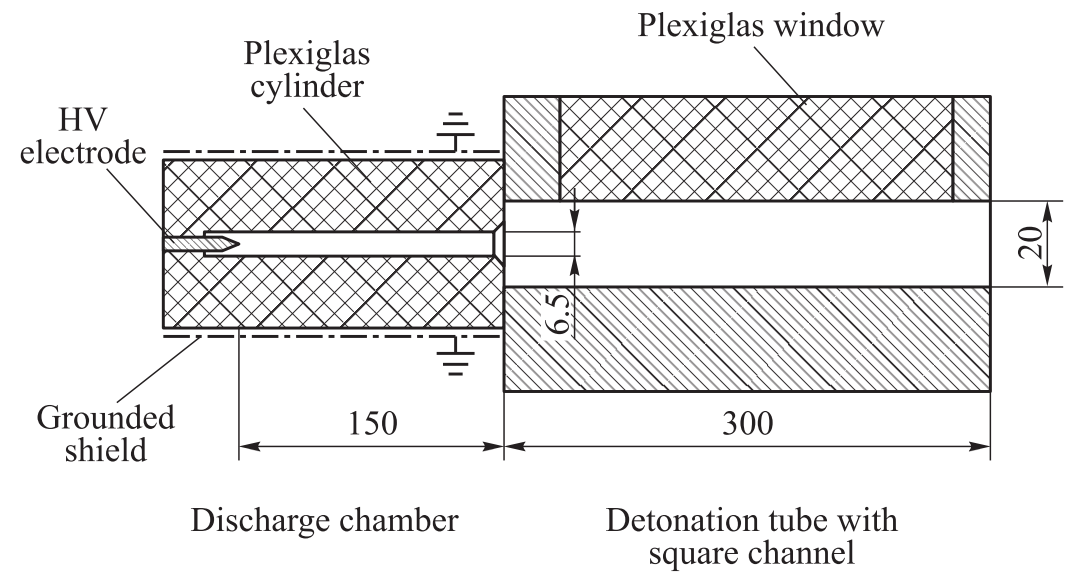

Figure 6 Scheme of detonation tube with single-cell geometry of the discharge chamber. Dimensions are in millimeters

square cross section and was $300 \mathrm{~mm}$ long. A set of photodiodes and pressure transducers was installed in the sidewalls for accurate flame front and shock wave velocity measurements. The discharge chamber and a sidewall of the detonation tube were made of plexiglas which allowed to perform direct optical measurements.

The imaging of discharge development through the plexiglas sidewall of the chamber was performed in air at pressures of 0.1 and 1 bar with the same ICCD camera. The images for $1 \mathrm{bar}$ and the discharge gap of $100 \mathrm{~mm}$ are presented in Fig. 7. It was seen that at this pressure, the streamers propagated along the discharge cell with a velocity over $5 \mathrm{~mm} / \mathrm{ns}$, filling most of the cell volume. After that, a high-current phase began, leading to a rapid overheating of the gas over the cell volume. Under the pressure of 0.1 bar, the streamer phase lasted less than $5 \mathrm{~ns}$, the streamer propagation velocity exceeding $20 \mathrm{~mm} / \mathrm{ns}$. Detonation initiation by this kind of discharge was studied for stoichiometric propane-oxygen mixture at pressures from 0.2 to 1 bar. Successful DDT was observed at $150 \mathrm{~mm}$ from the discharge chamber output at a minimum pressure of 0.3 bar; the DDT time did not exceed $300 \mu \mathrm{s}$. The ICCD imaging of the ignition and the DDT processes showed that the mixture all over the discharge cell volume ignited within $5 \mu$ s after the discharge. The ignition delay time was short due to the high temperatures of the gas attained during the high-current phase of the discharge. At 1 bar, the chemical energy stored inside the volume of the discharge chamber $(\sim 70 \mathrm{~J})$ was comparable to the energy of a direct detonation initiation for the case $(\sim 100 \mathrm{~J})[19]$. This allowed the DDT to occur via a mechanism similar to the direct initiation of detonation: a stationary detonation wave was observed less than two tube diameters away from the discharge chamber. At the same 

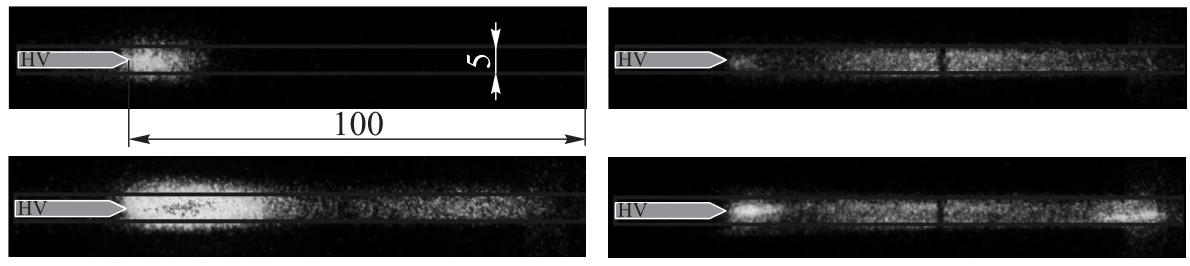

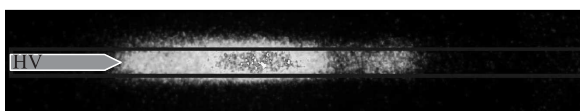

(a)

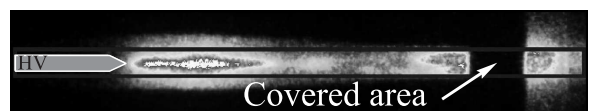

(b)

Figure 7 Images of discharge development in the single-cell geometry. Air, 1 bar: (a) 0-15 ns: streamer phase; (b) 15-30 ns: gap closure phase

time, the energy input in the discharge depended on the mixture density and composition and did not exceed 5 J. Furthermore, a successful detonation onset was also obtained when no high-current phase of the discharge was observed, i.e., no discharge gap closure occurred, which was the result of a substantially lower amplitude of the high-voltage pulse. The energy input was substantially lower in that case. This mode of discharge development and detonation initiation is under study at present.

\section{CONCLUDING REMARKS}

Three installations have been assembled to experimentally study detonation initiation by high-voltage nanosecond and microsecond discharges. Images of the discharge development were taken with an ICCD camera with nanosecond temporal resolution in all cases. The nanosecond pulsed discharge developed quasihomogeneously over the cross section of a distributed electrode system within the first $50 \mathrm{~ns}$, effectively ionizing and dissociating the mixture in a bulk volume. The microsecond discharge developed into a localized spark discharge after $50 \mathrm{~ns}$ at atmospheric pressure.

Under initiation by the distributed nanosecond discharge in a 140-millimeter diameter smooth detonation tube, a successful DDT was observed at 3 tube diameters from the discharge chamber in all $\mathrm{C}_{3} \mathrm{H}_{8} / \mathrm{C}_{4} \mathrm{H}_{10}+5 \mathrm{O}_{2}+x \mathrm{~N}_{2}$ mixtures with $\mathrm{N}_{2}$ concentration up to $38 \%$. The energy input did not exceed $3 \mathrm{~J}$, the DDT time was less than $1 \mathrm{~ms}$. Under initiation by the localized microsecond discharge in a 53-millimeter diameter smooth detonation tube, the DDT was observed at higher initial pressures for the same mixtures as compared to the nanosecond ignition. Thus, localized microsecond discharge has been shown to be substantially less efficient in terms of detonation onset when compared with 
the distributed nanosecond discharge. At the same time, the ignition delay times under the microsecond excitation in all mixtures under study were significantly lower as compared to the nanosecond ignition, due to the local nature of energy deposition in the microsecond discharge.

The detailed study of detonation initiation by nanosecond discharges in the single-cell discharge geometry revealed a mechanism similar to a direct initiation of detonation. Detonation was initiated by a discharge with an energy input of $\sim 5 \mathrm{~J}$ which is an order of magnitude lower than that necessary for the direct initiation for the case. The ICCD imaging of the discharge development, ignition, and DDT showed that the mixture ignited simultaneously over the volume of the discharge chamber due to gas overheating during the high-current phase of the discharge. The consequent chemical energy release led to a rapid detonation wave formation: a successful DDT in a stoichiometric propane-oxygen mixture at an initial pressure of 0.3 bar in a smooth tube of $20 \times 20 \mathrm{~mm}$ cross section was observed at $150 \mathrm{~mm}$ from the discharge chamber output; the DDT time did not exceed $300 \mu \mathrm{s}$. Effective detonation onset in the streamer mode under a lower amplitude of the high-voltage pulse also points at the possibility of Zel'dovich's gradient mechanism realization.

\section{ACKNOWLEDGMENTS}

This research was partially supported by the European Office of Aerospace Research and Development/ Civilian Research and Development Foundation (Projects GAP 1349 and RUP2-1512-MO-06), General Electric Global Research Center (Contract A02), Global Energy Foundation (Grant MG-2006/04/6), National Agency for Science and Innovation (Contract 02.442.11.7335), Russian Foundation for Basic Research (Grant 02-03-33376). The research was also supported by an individual grant from National Agency for Education in the framework of the Program for development of scientific potential of higher education, "The Study of Kinetics of Complex Reactive Systems under Action of High-Voltage Nanosecond Pulses."

\section{REFERENCES}

1. Bull, D. C., J. E. Elsworth, and G. Hooper. 1978. Initiation of spherical detonation in hydrocarbon/air mixtures. Acta Astronautica 5(11):997-1008.

2. Schultz, E., E. Wintenberger, and J.E. Shepherd. 1999. Investigation of deflagration to detonation transition for application to pulse detonation engine ignition systems. 16th JANNAF Propulsion Symposium Proceedings. Chemical Propulsion Information Agency.

3. Brown, C. J., and G. O. Thomas. 2000. Experimental studies of ignition and transition to detonation induced by the reflection and diffraction of shock waves. Shock Waves 10(1):23-32. 
4. Jackson, S. I., and J.E. Shepherd. 2002. Initiation systems for pulse detonation engines. AIAA Paper No. 2002-2627.

5. Shepherd, J.E., J. Austin, S. Jackson, M. Cooper, F. Pintgen, T. Chao, and D. Lieberman. 2002. Detonation initiation and propagation. 15th ONR Propulsion Meeting Proceedings. University of Maryland, USA. 161-66.

6. Smirnov, N. N., and V.F. Nikitin. 2004. Effect of channel geometry and mixture temperature on detonation-to-deflagration transition in gases. Combust. Explosion Shock Waves 40(2):186-99.

7. Sorin, R., R. Zitoun, and D. Desbordes. 2006. Optimization of the deflagration to detonation transition: Reduction of length and time of transition. Shock Waves 15(2):137-45.

8. Higgins, A. J., P. Pinard, A. C. Yoshinaka, and J. H.S. Lee. 2001. Sensitization of fuel-air mixtures for deflagration to detonation transition. In: High-speed deflagration and detonation: Fundamentals and control. Eds. G. Roy, S. Frolov, D. Netzer, and A. Borisov. Moscow, Russia: ELEX-KM Publ. 45-62.

9. Frolov, S. M., V. Ya. Basevich, V.S. Aksenov, and S. A. Polikhov. 2002. Initiation of spray detonation by successive triggering of electric discharges. In: Advances in confined detonations. Eds. G. Roy, S. Frolov, R. Santoro, and S. Tsyganov. Moscow, Russia: TORUS PRESS. 150-57.

10. Lee, J. H. S., R. Knystautas, and C. M. Guirao. 1974. Critical power density for direct initiation of unconfined gaseous detonationss. 15th Symposium (International) on Combustion Proceedings. Pittsburgh, USA: The Combustion Institute. 53.

11. Liu, J. B., P. D. Ronney, and M. A. Gundersen. 2002. Premixed flame ignition by transient plasma discharges. 29th Symposium (International) on Combustion. Sapporo, Japan: The Combustion Institute.

12. Wang, F., C. Jiang, A. Kuthi, M. A. Gundersen, C. Brophy, J. O. Sinibaldi, and L. C. Lee. 2004. Transient plasma ignition of hydrocarbon-air mixtures in pulse detonation engines. AIAA Paper No. 2004-0834.

13. Bozhenkov, S.A., S.M. Starikovskaia, and A.Yu. Starikovskii. 2003. Nanosecond gas discharge ignition of $\mathrm{H}_{2}$ and $\mathrm{CH}_{4}$ containing mixtures. Combust. Flame 133(1):133-46.

14. Kukaev, E. N., D. L. Tsyganov, V.P. Zhukov, S.M. Starikovskaia, and A. Yu. Starikovskii. 2004. Deflagration-to-detonation control by non-equilibrium gas discharges and its applications for pulsed detonation engine. AIAA Paper No. 2004-870.

15. Zel'dovich, Ya. B., V. B. Librovich, G. M. Makhviladze, and G. I. Sivashinskii. 1970. On the onset of detonation in a nonuniformly heated gas. J. Appl. Mech. Tech. Phys. 11(2):264-70.

16. Zhukov, V.P., and A. Yu. Starikovskii. 2006. Effect of a nanosecond gas discharge on deflagration to detonation transition. Combust. Explosion Shock Waves 42(2):195204.

17. Zhukov, V.P., A.E. Rakitin, and A. Yu. Starikovskii. 2006. Initiation of detonation by nanosecond gas discharge. AIAA Paper No. 2006-952.

18. Starikovskii, A. Yu. 2006. The method of initiation of ignition, intensification of combustion or reforming of fuel-air and fuel-oxygen mixtures. Patent PCT/IB $2006 / 003106$.

19. Kaneshige, M., and J. E. Shepherd. 1997. Detonation database. GALCIT. Technical Report FM97-8. 